\title{
Two-Dimensional Material Interface Engineering for Efficient Perovskite Large- Area Modules
}

${ }_{4}$ Antonio Agresti, ${ }^{\dagger \dagger, \text { II }}$ Sara Pescetelli, ${ }^{\dagger, \text { II }}$ Alessandro Lorenzo Palma, ${ }^{\dagger}$ B Beatriz Martín-García, ${ }^{\S}, \|$ ${ }_{5}$ Leyla Najafi, ${ }_{6}^{\S}$ Sebastiano Bellani, ${ }^{\S}$ Iwan Moreels, $\|$ Mirko Prato, ${ }^{\perp}{ }^{\circledR}$ Francesco Bonaccorso, ${ }^{*},{ }^{\S},{ }(0)$ 6 and Aldo Di Carlo*,

$7^{\dagger}$ CHOSE - Centre for Hybrid and Organic Solar Energy, Department of Electronic Engineering, University of Rome Tor Vergata, via 8 del Politecnico 1, 00133 Rome, Italy

9 "LASE - Laboratory of Advanced Solar Energy, National University of Science and Technology "MISiS”, Moscow 119049, Russia $10{ }^{\S}$ Graphene Laboratories, Istituto Italiano di Tecnologia, via Morego 30, 16163 Genova, Italy

11 "Nanochemistry Department, Istituto Italiano di Tecnologia, via Morego 30, 16163 Genova, Italy

${ }_{12}{ }^{\perp}$ Materials Characterization Facility, Istituto Italiano di Tecnologia, via Morego 30, 16163 Genova, Italy

13 \#BeDimensional S.p.A., Via Albisola 121, 16163 Genova, Italy

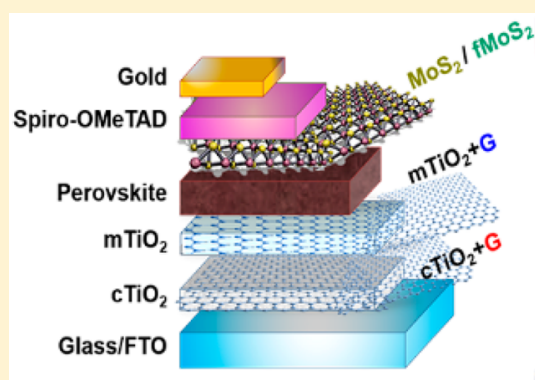

PCE $=13.4 \%$

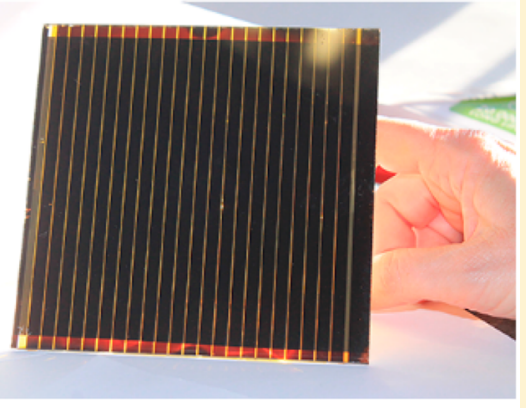

Active area $108 \mathrm{~cm}^{2}$

15 ABSTRACT: In this work, we demonstrate the successful application of two-dimensional (2D) materials, i.e., graphene and functionalized $\mathrm{MoS}_{2}$, in perovskite solar cells (PSCs) by interface engineering the standard mesoscopic $n-i-p$ structure. The use of $2 \mathrm{D}$ materials has the dual role to improve both the stability and the overall power conversion efficiency (PCE) of the PSCs compared to standard devices. The application of 2D materials is successfully extended to large-area perovskite solar modules (PSMs), achieving PCEs of $13.4 \%$ and $15.3 \%$ on active areas of $108 \mathrm{~cm}^{2}$ and $82 \mathrm{~cm}^{2}$, respectively. This performance results in record-high active area-indexed aperture PCE (AIAPCE) of $1266.5 \% \mathrm{~cm}^{2} . \mathrm{In}^{\circ}$ addition, the $2 \mathrm{D}$ materials-based PSMs show a stability under a prolonged $(>1000 \mathrm{~h})$ thermal stress test at $65^{\circ} \mathrm{C}($ ISOSD2), representing a crucial advancement in the exploitation of perovskite photovoltaic technology.

I $\mathrm{n}$ recent years, lead-halide perovskite solar cells (PSCs) have catalyzed the attention of the scientific community, with power conversion efficiency (PCE) exceeding 20\%, 26 by using cost-effective and potentially scalable solution 27 processing approaches. ${ }^{1,2}$ In particular, the global research 28 effort boosted the PCE of PSCs up to $24.2 \%$ for single29 junction $^{3}$ and $27.3 \%$ for tandem perovskite/silicon ${ }^{4}$ solar cells. 30 Despite these important achievements, long-term stability ${ }^{5}$ and 31 scalability $^{6}$ are still the major constraints for the market entry 32 of the perovskite photovoltaic technology. ${ }^{7,8}$ In fact, the 33 photoactive lead-halide perovskites typically lack stability due to their hygroscopicity and propensity to back-convert into 34 their precursors during exposure to moisture, ${ }^{9}$ oxygen, ${ }^{10,11}$ and 35 light illumination. ${ }^{10,12}$ Moreover, they experience a tetragonal- 36 to-cubic phase transition at the temperature reached during 37 typical solar cell operation $\left(>80{ }^{\circ} \mathrm{C}\right),{ }^{13}$ resulting in making 38 them unfit for standard solar module certifications. ${ }^{14,15}$ In 39 addition, the deposition of both pin-hole-free homogeneous 40

Received: May 27, 2019

Accepted: June 27, 2019

Published: June 27, 2019 
41 high-crystallinity perovskite films and effective charge transport 42 layers (CTLs) by industrial approaches is still a tough obstacle 43 toward the development of large-area PSCs with PCE 44 comparable to those achieved by lab-scale (less than few $45 \mathrm{~cm}^{2}$ ) cells. ${ }^{16-18}$ In particular, the nucleation and crystal growth 46 kinetics for high-quality perovskite film are attained by 47 optimizing the choice of the solvent ${ }^{19,20}$ and the solvent 48 drying rate ${ }^{21}$ and possibly using antisolvent crystallization. ${ }^{22,23}$ 49 However, this optimization pathway could not straightfor50 wardly meet the requirements of large-area linear and/or roll51 to-roll (R2R) coatings $^{24}$ (e.g., doctor blading ${ }^{25}$ and gravure 52 printing, $^{26}$ as well as slot-die and spray coating ${ }^{27-29}$ ). Beyond 53 the issues relating to the perovskite layer, the choice of the 54 architecture and the interface engineering of the PSCs also play 55 a crucial role in achieving valuable upscaling criteria, since 56 pinhole-free, homogeneous, and, eventually, compact CTLs are 57 mandatory to reduce PCE losses, ${ }^{30-34}$ i.e., to improve the 58 extraction of the photogenerated charge carriers (i.e., the short 59 circuit current density, $J_{\text {sc }}$ and the open-circuit voltage, $\left.V_{\mathrm{OC}}\right) .^{35}$ 60 Thereby, both $\mathrm{n}-\mathrm{i}-\mathrm{p}$ planar ${ }^{7,36}$ and mesoscopic architec61 tures $^{37,38}$ have been investigated for the realization of large62 area PSCs and perovskite solar modules (PSMs), ${ }^{16}$ as also 63 reported by several PV companies (e.g., Microquanta Semi64 conductor, Solliance, Saule Technologies, and Greatcell Solar, 65 just to cite a few). In favor of the planar structures, these can 66 be produced through low-temperature material deposition 67 processes $\left(<180{ }^{\circ} \mathrm{C}\right)$, which make feasible the realization of 68 flexible devices produced by using high-throughput R2R 69 techniques. ${ }^{39}$ So far, the largest solution-processed and 70 efficient PSMs (e.g., aperture area $=16.07 \mathrm{~cm}^{2}$ and PCE = $7114.9 \%)^{40}$ are based on planar $\mathrm{n}-\mathrm{i}-\mathrm{p}$ architecture, as obtained 72 by depositing a tin oxide $\left(\mathrm{SnO}_{2}\right)$-based electron transport layer 73 (ETL) via spin ${ }^{41} /$ slot-die coating, ${ }^{40}$ and $2,2^{\prime}, 7,7^{\prime}$-tetrakis $(N, N$ 74 di-4-methoxyphenylamino)-9,9' -spirobifluorene (spiro-OMe$75 \mathrm{TAD}$ )-based hole transport layer (HTL) via doctor blad$76 \mathrm{ing}^{41} /$ spin coating. ${ }^{40}$ Moreover, a planar architecture based on 77 a $\mathrm{SnO}_{2}$ ETL and carbazole derivative HTL, demonstrating 78 remarkable stability under $70 \mathrm{~mW} / \mathrm{cm}^{2}$ in the case of small 79 area devices, ${ }^{42}$ achieved a PCE of $14.9 \%$ stable over $100 \mathrm{~h}$ in a $807.25 \mathrm{~cm}^{2}$ active area mini-module. ${ }^{43}$ By replacing $\mathrm{SnO}_{2}$ with a 81 compact $\mathrm{TiO}_{2}\left(\mathrm{cTiO}_{2}\right)$ ETL, as realized by means of high 82 temperature $\left(450{ }^{\circ} \mathrm{C}\right)$ spray pyrolysis deposition ${ }^{44}$ or e-beam 83 evaporation, ${ }^{45} \mathrm{PCE}$ losses have been further reduced to reach a 84 remarkable PCE $>17 \%$ on $10.36 \mathrm{~cm}^{2}$ active area ${ }^{44}$ and a PCE $85>10 \%$ on an active area of $\sim 170 \mathrm{~cm}^{2}{ }^{45}$ Recently, PSMs based 86 on inverted planar $\mathrm{p}-\mathrm{i}-\mathrm{n}$ architectures have also been 87 produced via electrochemically assembling metal-filamentary 88 nanoelectrodes. ${ }^{46}$ Although these innovative PSMs exhibited a 89 PCE exceeding $14 \%$ and a remarkable stability (PCE loss of $90 \sim 20 \%$ after $>180 \mathrm{~h}$ at $85{ }^{\circ} \mathrm{C}$ and $85 \%$ humidity rate, HR), their 91 active area was limited to $9.06 \mathrm{~cm}^{2}, 40,41,44,45$ indicating the 92 need to confirm their prompt and facile upscaling. Overall, the 93 aforementioned examples have demonstrated that the planar 94 architectures still face several issues that need to be overcome 95 to design and realize large-area solution processed PSMs with 96 high PCEs. Therefore, it is not by chance that the best 97 performing (both in terms of PCE and stability) large area 98 PSMs (size $>40 \mathrm{~cm}^{2}$ ) have been demonstrated by using 99 mesoporous architectures. ${ }^{17,47}$ In particular, carbon-based $100 \mathrm{PSMs}^{48,49}$ promise low-cost and superior stability in air 101 compared to their counterparts based on metal contacts. ${ }^{48,49}$ 102 For example, carbon-based PSMs, produced by infiltrating 103 perovskite over $\mathrm{cTiO}_{2} /$ mesoporous $\mathrm{TiO}_{2}\left(\mathrm{mTiO}_{2}\right) /$ zirconium oxide $\left(\mathrm{ZrO}_{2}\right)$ / carbon paste stacks, having an active area of 47.6104 $\mathrm{cm}^{2}$, have exhibited a stable PCE of $10.1 \%$ over more than 105 $10000 \mathrm{~h}$ under 1 sun illumination. ${ }^{33}$ However, when the 106 carbon structure was further scaled up to a record-high active 107 area of $198 \mathrm{~cm}^{2}$, the PCE dropped significantly (i.e., $\left.6.6 \%\right)^{50} 108$ due to the irregular infiltration process of the perovskite film. 109 Meanwhile, traditional mesoscopic architectures with metal 110 contacts have been reported for PSMs with record-high 111 PCEs, ${ }^{17}$ achieved by engineering the interfaces between the 112 different composing layers. In particular, the interface 113 engineering based on two-dimensional (2D) materials has 114 recently been proposed as an effective way to improve the PCE 115 and the stability of solution-processed PSCs. ${ }^{51,52}$ For example, 116 we have recently proposed graphene interface engineering 117 (GIE) as a strategy to demonstrate PSMs with a PCE of $12.6 \% 118$ on an active area of $50 \mathrm{~cm}^{2} .{ }^{53}$ Here, GIE consists of using 119 graphene and graphene-related materials (GRM) in the form 120 of interlayers (also named active buffer layers, ABLs) at 121 perovskite/CTL interfaces and/or as dopant for standard 122 CTLs. ${ }^{30,54-58}$ Previous investigations on mesoscopic $\mathrm{n}-\mathrm{i}-\mathrm{p} 123$ architectures (glass/fluorine tin oxide $(\mathrm{FTO}) / \mathrm{cTiO}_{2} /$ gra- 124 phene-doped $\mathrm{mTiO}_{2}\left(\mathrm{mTiO}_{2}+\mathrm{G}\right) /$ perovskite/spiro-OMe- 125 $\mathrm{TAD} /$ gold $(\mathrm{Au})$ ) have demonstrated that graphene flakes 126 incorporated into the $\mathrm{mTiO}_{2}$ have a bifunctional role. On the 127 one hand, they improve the perovskite morphology by 128 reducing the density of the trap states located at the $\mathrm{mTiO}_{2} / 129$ perovskite interface, ${ }^{54,55}$ thus limiting the irreversible dissoci- 130 ation of perovskite materials. ${ }^{59}$ On the other hand, they 131 promote the electron extraction from the perovskite to the 132 ETL, as well as the electron transport within the ETLs toward 133 the current collector (i.e., the FTO) ${ }^{55}$ Despite the use of 134 graphene being able to retard the degradation of the 135 perovskite/ETL interface, the instability of the methylammo- 136 nium lead iodide perovskite $\left(\mathrm{MAPbI}_{3}\right)$ still represented a limit 137 to pass the standard stress test condition defined by the C450 138 testing protocol for photovoltaic modules. ${ }^{60,61}$ In fact, $\mathrm{MAPbI}_{3} 139$ undergoes a fast degradation upon exposure to moisture, due 140 to its low formation energy, which causes its decomposition to 141 solid $\mathrm{PbI}_{2}$ and gaseous methylamine and hydrogen halide 142 under moderate temperature $\left(60^{\circ} \mathrm{C}\right)$ stresses. ${ }^{62}$ Furthermore, 143 perovskite heating under operating conditions has been 144 reported, causing degradation pathways attributed to atom 145 migration from the $\mathrm{Au}$ electrode toward $\mathrm{MAPbI}_{3}{ }^{22,27}$ In fact, 146 $\mathrm{Au}$, as well as other electrode metals, can react with $\mathrm{MAPbI}_{3}, 147$ creating nonradiative recombination centers, i.e., PCE losses. ${ }^{63} 148$ Finally, voltage bias and/or thermal drift also cause the 149 movements of ions composing $\mathrm{MAPbI}_{3}$, inducing defects (e.g., 150 iodine vacancies) ${ }^{64,65}$ that degrade the interface of the device 151 until its failure. ${ }^{59}$

With the aim to thermally stabilize the most efficient PSCs 153 (as well as the corresponding PSMs), several perovskite 154 absorber optimizations and new device architecture engineer- 155 ing strategies have been proposed. ${ }^{66}$ First, thermally stable 156 mixed-cation hybrid lead halide perovskites using methyl- 157 ammonium (MA), formamidinium (FA), and cesium (Cs) 158 cations have been successfully designed by tuning the 159 Goldschmidt tolerance factor. ${ }^{67}$ Second, novel hole transport 160 materials have been screened for stabilizing perovskite/HTL 161 interfaces. $^{61,68}$ In fact, the well-known weak adhesion of the 162 most established mild organic hole transport materials (e.g., 163 spiro-OMeTAD or poly(triarylamine), PTAA) to the perov- 164 skite surface ${ }^{69,70}$ can trigger PCE losses. ${ }^{71}$ In addition, the poor 165 hole mobility of the spiro-OMeTAD (in the order of $10^{-4} \mathrm{~cm}^{2} 166$ 
a)

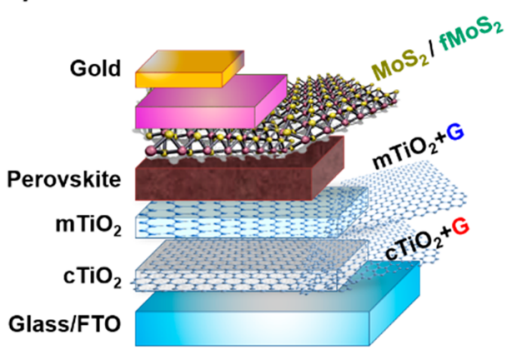

b)

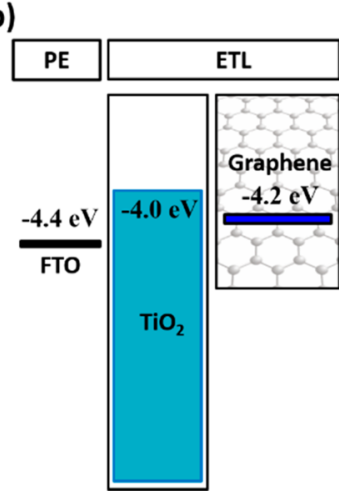

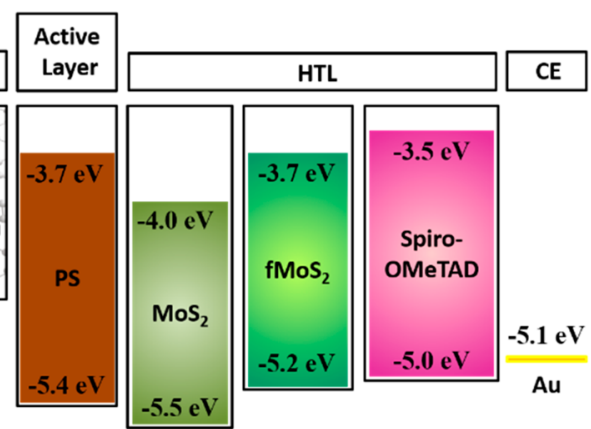

Figure 1. (a) 2D material-engineered PSC architecture and (b) its energy band diagram. The work function values for FTO, TiO ${ }_{2}$, and graphene have been taken from refs 77-79. The highest occupied molecular orbital (HOMO) and lowest unoccupied molecular orbital (LUMO) levels for perovskite and spiro-OMeTAD have been taken from refs $80-82$, respectively. The energy band edge positions for MoS ${ }_{2}$ and $\mathrm{fMoS}_{2}$ have been experimentally determined by optical absorption spectroscopy and ultraviolet photoelectron spectroscopy measurements, as detailed in the Supporting Information.

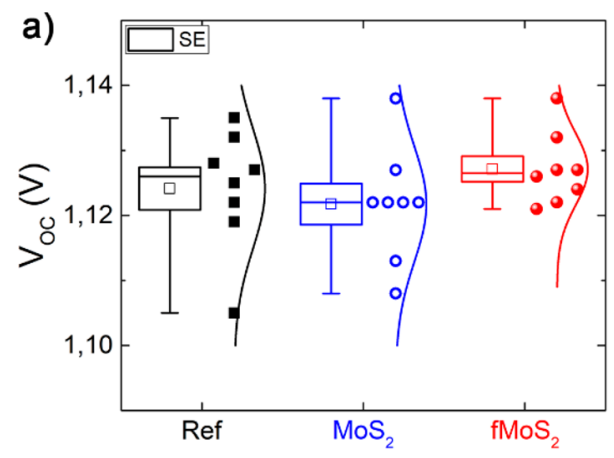

c)

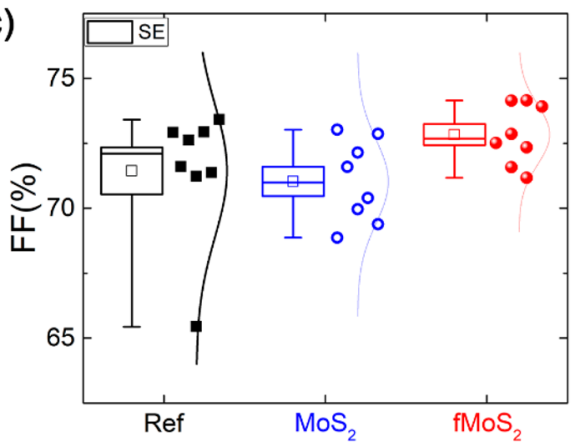

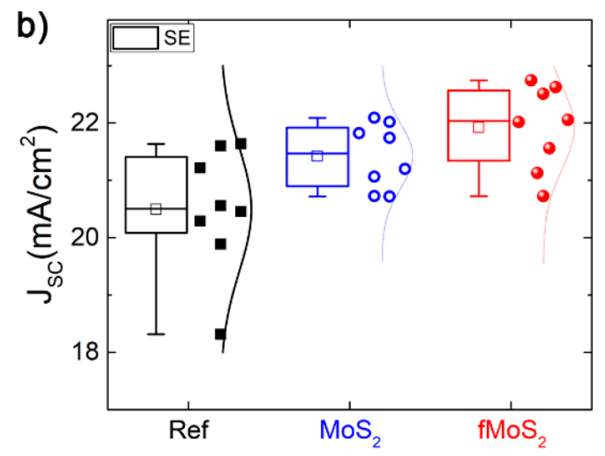

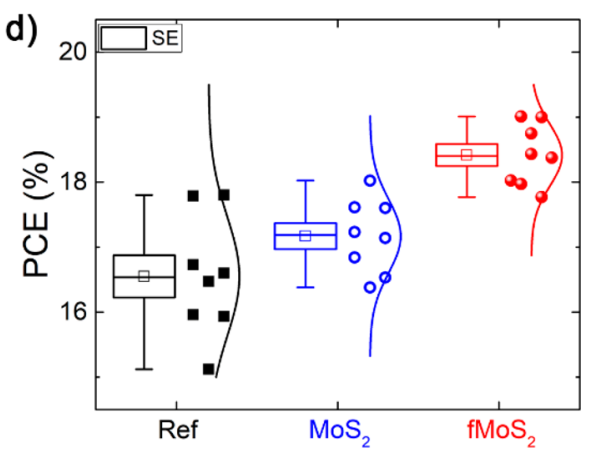

Figure 2. Photovoltaic parameter statistics for the investigated PSCs extracted by the $I-V$ characteristics under 1 sun illumination: (a) $V_{\mathrm{OC}}$, (b) $J_{S C}$, (c) FF, and (d) PCE. The statistics were measured on 8 PSCs for each architecture.

$\left.167 \mathrm{~V}^{-1} \mathrm{~s}^{-1}\right)^{72,73}$ requires the use of redox active p-type dopants, 168 such as Li-bis(trifluoromethanesulfonyl)imide (Li-TFSI), ${ }^{73}$ 169 which intensify the device degradation because of their 170 propensity to absorb moisture from the air and become 171 dissolved in the moisture itself. ${ }^{74}$ The photo-oxidation ${ }^{75}$ and 172 the crystallization at temperature $>80^{\circ} \mathrm{C}^{76}$ of spiro-OMeTAD 173 can further damage its properties. To eliminate such issues, 174 inorganic hole transport materials, such as copper thiocyanate $175(\mathrm{CuSCN}),{ }^{61,68}$ have shown improved thermal ${ }^{68}$ and light 176 soaking stability relative to those of organic materials. ${ }^{61}$ 177 However, the hazardous solvents (e.g., diethyl sulfide) usually 178 used to disperse $\mathrm{CuSCN}^{61}$ require a well-controlled environ179 ment for the subsequent material deposition, increasing the 180 associated costs in large-scale production chains.

181 In this work, we report the combination of thermally stable 182 mixed-cation perovskite with $2 \mathrm{D}$ material-engineered meso- scopic $n-i-p$ architecture as an effective method to design and 183 realize PSMs. In particular, graphene-based ETLs are exploited 184 to accelerate the electron extraction/collection, as well as to 185 control the perovskite morphology over the mesoscopic 186 scaffold. Furthermore, chemically functionalized molybdenum 187 disulfide $\left(\mathrm{fMoS}_{2}\right)$ is used as an efficient $\mathrm{ABL}$ at the perovskite/ 188 HTL interface for improving the hole injection/collection at 189 the counter-electrode (CE). A thermal-assisted spray coating 190 technique is exploited to deposit $\mathrm{fMoS}_{2} \mathrm{ABL}$ without 191 damaging the underlying perovskite film. Our 2D material- 192 engineered PSMs have shown a PCE of $13.4 \%$ and $15.3 \%$ on 193 active areas of $108 \mathrm{~cm}^{2}$ and $82 \mathrm{~cm}^{2}$, respectively. Moreover, the 194 use of 2D materials allows the PSMs to achieve a satisfactory 195 lifetime, displaying a PCE retention of 75\%, under prolonged 196 thermal stress at $65{ }^{\circ} \mathrm{C}$ (ISOS-D2) over the first $1000 \mathrm{~h}, 197$ 

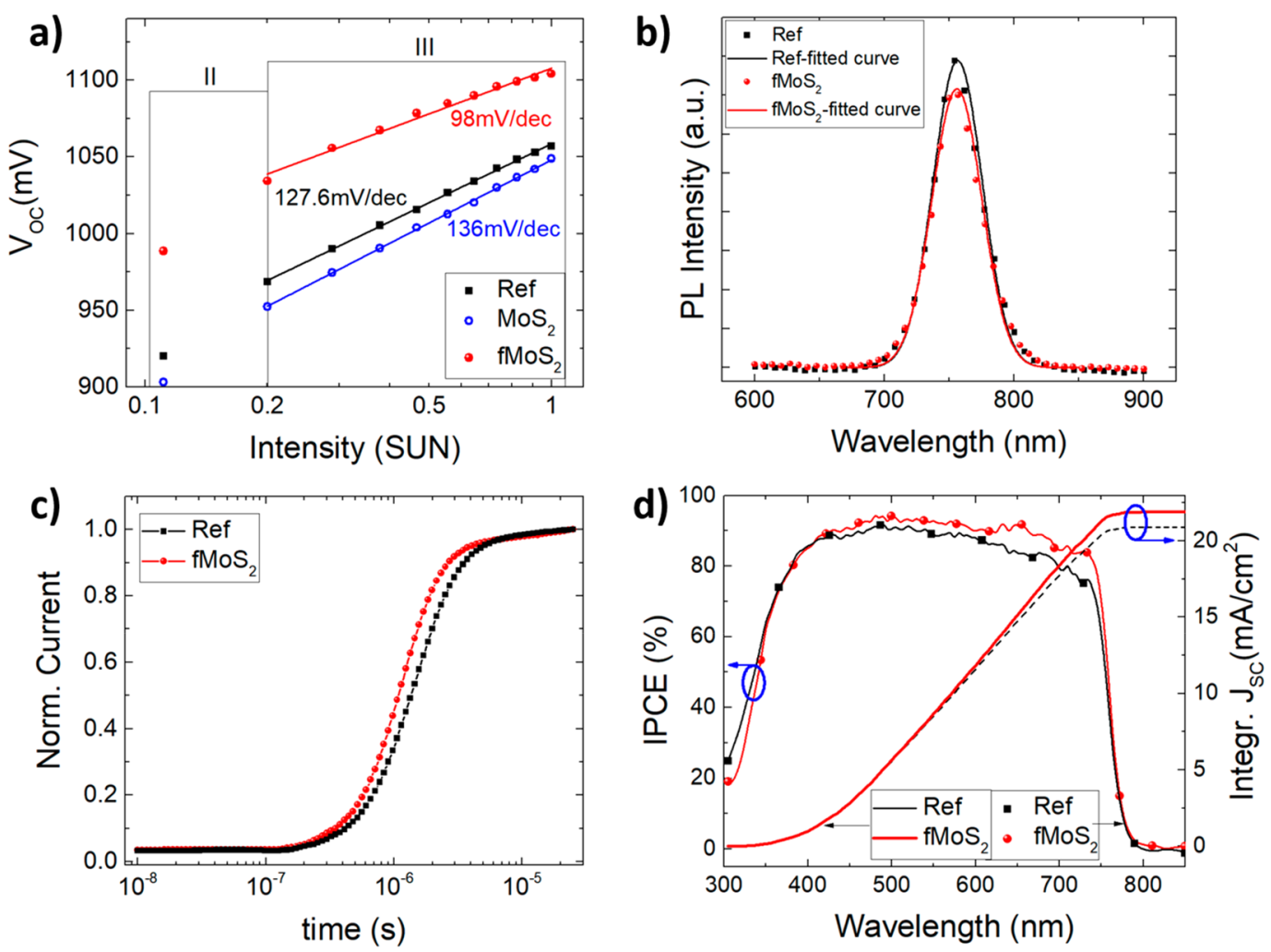

Figure 3. Transient and electro-optical analysis on as-produced PSCs. (a) $V_{\mathrm{OC}}$ vs $\log \left(P_{\text {inc }}\right)$ plot for the different devices with and without ABLs. (b) Photoluminescence (PL) emission from the devices without Au CE. (c) Transient photocurrent profile acquired by switching on the LED light for $\mathrm{fMoS}_{2}$-based and reference devices. (d) Incident-photon-to-current conversion efficiency (IPCE) spectra and the corresponding integrated $J_{\mathrm{SC}}$ for $\mathrm{fMoS}_{2}$-based and reference devices. All the measurements in (c) and (d) are acquired on complete devices.

198 confirming the crucial role of $2 \mathrm{D}$ material-based layers in 199 preventing perovskite/CTL interface degradation.

200 Small-Area Devices. The proposed 2D material-engineered 201 PSC architecture is depicted in Figure 1a, the following are the 202 details: glass/FTO/ $\left./ \mathrm{CTiO}_{2}+\mathrm{G}\right) / \mathrm{mTiO}_{2}+\mathrm{G} /$ perovskite/spiro$203 \mathrm{OMeTAD} / \mathrm{MoS}_{2}$ or $\mathrm{fMoS}_{2} / \mathrm{Au}$. The graphene-doped $\mathrm{cTiO}_{2}$ $204\left(\mathrm{cTiO}_{2}+\mathrm{G}\right)$ layer was deposited by the same spray pyrolysis 205 protocol from the $\mathrm{cTiO}_{2}$ dispersion doped with graphene ink $206(1 \mathrm{vol} \%)$ dispersed in a mix of ethanol and water $(80: 20, \mathrm{v} / \mathrm{v})$, 207 while $\mathrm{fMoS}_{2}$ (dispersed in 2-propanol) ABL was uniformly 208 sprayed on large-area substrates by a thermal-assisted spray 209 coating technique. More in detail, during the spray deposition, 210 the module substrates were kept at $80{ }^{\circ} \mathrm{C}$ to speed up the 211 evaporation of the $\mathrm{PMoS}_{2}$ ink solvent and to prevent the 212 perovskite degradation, in agreement with protocols previously 213 reported. ${ }^{30}$ The experimental details regarding the device 214 manufacturing and the characterization tools used for device 215 analysis are reported in the Supporting Information.

216 In particular, the prototypical ETL $\left(\mathrm{cTiO}_{2} / \mathrm{mTiO}_{2}\right)$ was 217 modified by the addition of graphene flakes into both the $218 \mathrm{cTiO}_{2}\left(\mathrm{cTiO}_{2}+\mathrm{G}\right)$ and the $\mathrm{mTiO}_{2}\left(\mathrm{mTiO}_{2}+\mathrm{G}\right)$. As reported in 219 our previous works, ${ }^{83}$ the insertion of graphene flakes into the $220 \mathrm{cTiO}_{2}$ decreases the series resistance of the cell, which 221 consequently exhibits high fill factor, FF (typically $>75 \%$ ), 222 compared to the reference without graphene flakes. ${ }^{84}$ Actually, 223 the graphene flakes provide effective electrically conductive 224 pathways to transport the electron toward the FTO electrode. 225 Alongside, the addition of the graphene flakes into the $\mathrm{mTiO}_{2}$ 226 improves the device PCE by increasing both the FF and short 227 circuit current $\left(I_{\mathrm{SC}}\right){ }^{53}$ In agreement with steady-state 228 photoluminescence (PL) and time-resolved photolumines- cence (TRPL) spectroscopy measurements, the perovskite 229 optimally crystallizes when it is wrapped into the $\mathrm{mTiO}_{2}+\mathrm{G}, 230$ enhancing the electron injection efficiency at the $\mathrm{mTiO}_{2}+\mathrm{G} / 231$ perovskite interface. ${ }^{55}$ Theoretical simulations have also 232 evidenced a ferroelectric distortion of the perovskite in contact 233 with graphene, which drives electron extraction from the 234 perovskite and hinders electron-hole recombination. ${ }^{85}$ Mean- 235 while, the presence of graphene in the bare $\mathrm{mTiO}_{2}$ layer 236 improves the overall electron transport toward the $\mathrm{cTiO}_{2}, 237$ decreasing the series resistance and, thus, the $\mathrm{FF}$ of the 238 device. ${ }^{55}$ As a further step for the realization of efficient PSCs, 239 an appropriate energy level tailoring at the perovskite/HTL 240 interface is pivotal to improve the hole extraction for the 241 perovskite to the HTL, eventually impeding the interface 242 degradation induced by charge trapping phenomena. ${ }^{59}$ In this 243 context, several 2D material-based films, mainly transition 244 metal dichalcogenides (TMDs), have been proposed as 245 effective ABLs at the perovskite/HTL interface. ${ }^{59,86-88} 246$ Among them, we exploited $\mathrm{MoS}_{2}$ flakes, as obtained by liquid 247 phase exfoliation (LPE) of bulk crystals in 2-propanol (see 248 Supporting Information, Figure S1). The as-produced 249 dispersion can be deposited over perovskite as an ABL by 250 thermal-assisted spray coating (resulted by heating the 251 substrate at $\left.80{ }^{\circ} \mathrm{C}\right) .{ }^{84,89}$ However, the $\mathrm{MoS}_{2}$ valence band 252 edge does not perfectly match with the perovskite highest 253 occupied molecular orbital (HOMO) level and possibly forms 254 an energy barrier for the hole extraction process. To avoid this 255 drawback, we have also produced chemically functionalized 256 $\mathrm{MoS}_{2}$ flakes $\left(\mathrm{fMoS}_{2}\right)$, by linking thiol of 3-mercaptopropionic 257 acid (MPA) moieties to the $\mathrm{MoS}_{2}$ surface via $\mathrm{S}-\mathrm{S}$ van der 258 Waals physisorption ${ }^{90}$ and/or S-vacancy passivation. ${ }^{91,92} 259$ 
a)

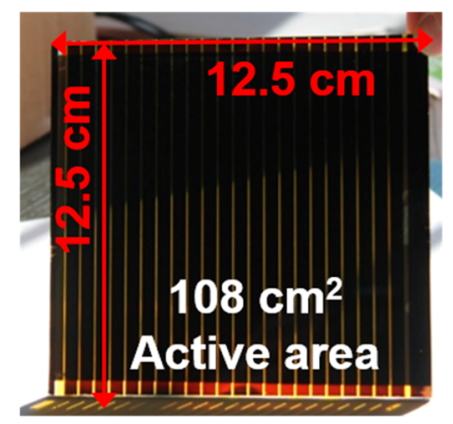

b)
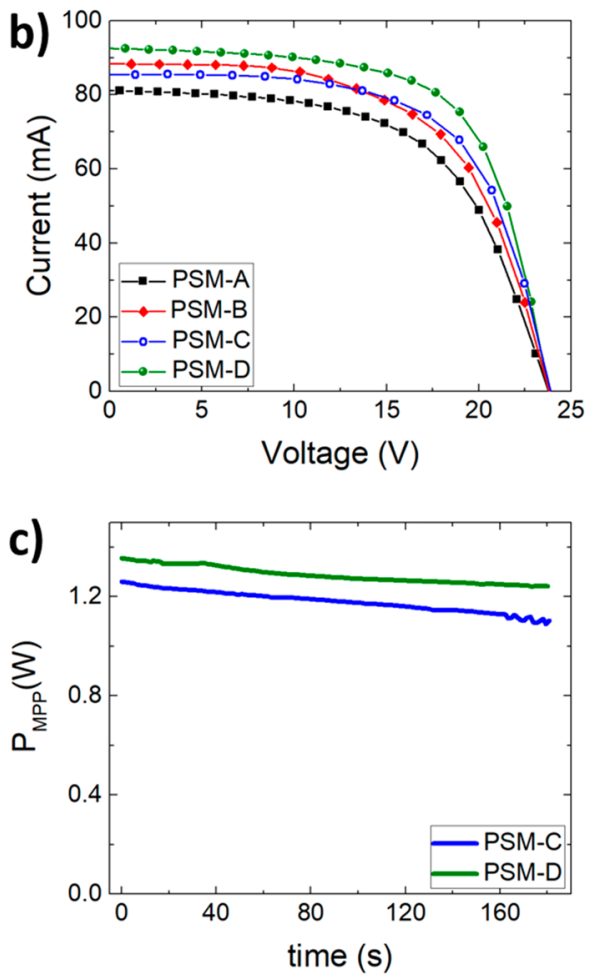

Figure 4. (a) Photograph of a representative large-area PSM (108 $\mathrm{cm}^{2}$ active area, $156.25 \mathrm{~cm}^{2}$ substrate area). (b) $I-V$ characteristics of tested PSMs. (c) Stabilized power at maximum power point $\left(P_{\mathrm{MPP}}\right)$ under 1 sun illumination for PSM-C and PSM-D.

260 Beyond chemically and electronically repairing the defective 261 lattice of the $\mathrm{MoS}_{2}$ flakes, ${ }^{91}$ the MPA-based functionalization is 262 effective to shift $\mathrm{MoS}_{2}$ energy bands up (see characterization 263 measurements in Figure S2). Actually, MPA has also been 264 recently exploited to shift the energy bands of $\mathrm{PbS}$ quantum 265 dots up, ${ }^{93}$ offering a versatile tool to engineering the interfaces 266 in optoelectronic devices. ${ }^{83}$ In our case, as sketched in Figure $267 \mathrm{lb}$, the upshift of the $\mathrm{MoS}_{2}$ energy bands has an immediate 268 dual role: (1) to align the valence band edge of $\mathrm{MoS}_{2}$ with the 269 HOMO level of the perovskite, improving the hole extraction 270 process, ${ }^{93}$ and (2) to shift the conduction band edge of $\mathrm{MoS}_{2}$ 271 above the LUMO level of the perovskite, restricting undesired 272 electron transfer (i.e., providing electron blocking proper273 ties). ${ }^{30}$

274 To assess the beneficial role of $\mathrm{fMoS}_{2}$ as $\mathrm{ABL}$, small-area 275 devices $\left(0.09 \mathrm{~cm}^{2}\right.$ active area) were fabricated using graphene276 based ETLs without (reference sample) and with $\mathrm{MoS}_{2}$ or $277 \mathrm{fMoS}_{2} \mathrm{ABLs}$ at the perovskite/HTM interface. Figure 2 reports 278 the photovoltaic parameter statistics for the various PSCs
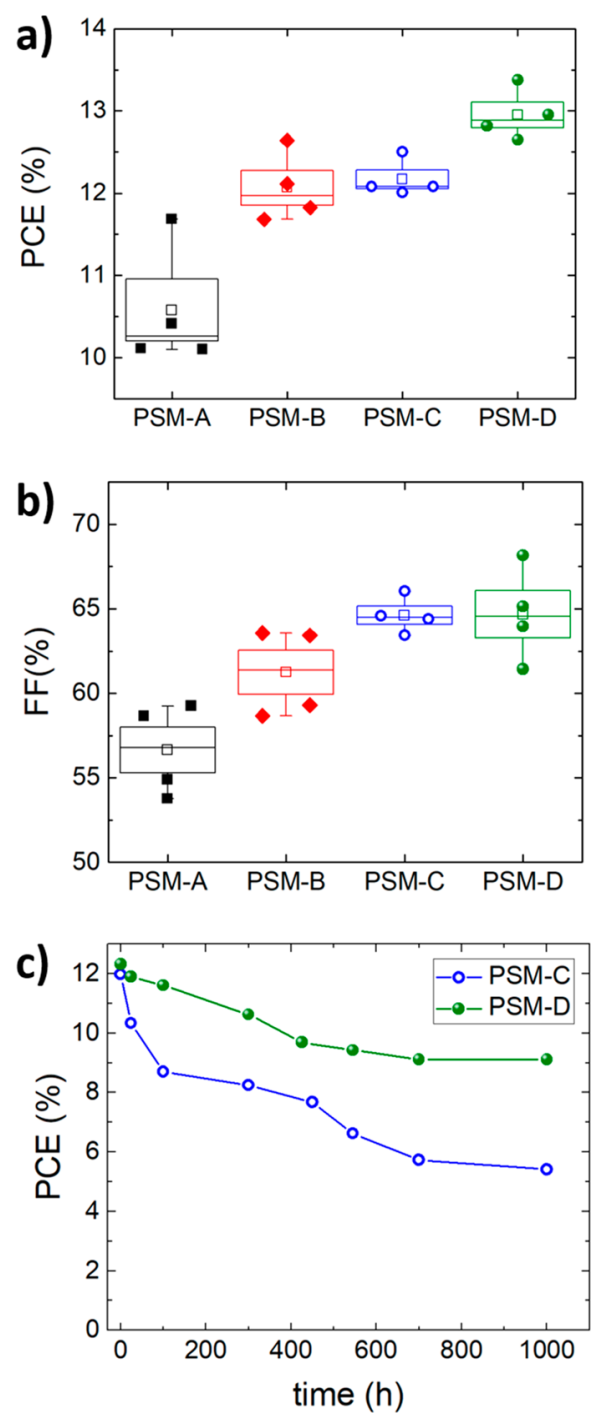

Figure 5. (a) PCE and (b) FF statistics for the various PSMs extracted by the corresponding $I-V$ characteristics under 1 sun illumination. (c) PCE trends vs time extracted by the $I-V$ characteristics under 1 sun illumination, periodically acquired during the prolonged thermal stress test at $65{ }^{\circ} \mathrm{C}$ (ISOS-D2) for PSM-C and PSM-D. The statistics were measured on four PSMs for each configuration.

extracted by the current-voltage $(I-V)$ characteristics under 1279 sun illumination.

Clearly, the insertion of the ABLs increases the PCE of the 281 PSCs compared to the reference architectures. More in detail, 282 the PCE increase is larger for cells with $\mathrm{fMoS}_{2}(+11.6 \%) 283$ compared to that of $\mathrm{MoS}_{2}$ cells $(+3.7 \%)$. In fact, although the 284 average $J_{\mathrm{SC}}$ increases for both ABL-based architectures $(+4.8 \% 285$ and $+7.2 \%$ for $\mathrm{MoS}_{2}$ and $\mathrm{fMoS}_{2}$, respectively) compared to 286 reference devices, the $\mathrm{FF}$ and the $V_{\mathrm{OC}}$ relatively increase only 287 for $\mathrm{fMoS}_{2}$-based devices ( $+2 \%$ and $+1 \%$, respectively). 288 Compared to both reference and $\mathrm{MoS}_{2}$-based cells, in 289 $\mathrm{fMoS}_{2}$-based devices, the increase of $\mathrm{FF}$ is attributed to a 290 well-balanced hole and electron extraction, while the correct 291 energy alignment between the perovskite HOMO and the 292 $\mathrm{fMoS}_{2}$ valence band edge explains the increase of the average 293 $V_{\text {OC. }}$. Both these effects synergistically boost the PCE of the 294 champion $\mathrm{fMoS}_{2}$-based cell up to $19.2 \%$ (averaged PCE of 295 $18.3 \%)$. 
297 The beneficial role of $\mathrm{fMoS}_{2}$ into the device architecture was 298 confirmed by both electrical and spectroscopic measurements. 299 First, $V_{\text {OC }}$ values were acquired by progressively increasing the 300 incident power $\left(P_{\text {inc }}\right)$ with a calibrated white LED, as shown in 301 the $V_{\text {OC }}$ vs $\log \left(P_{\text {inc }}\right)$ plot (Figure $\left.3 \mathrm{a}\right)$. In fact, the analysis of the 302 latter allows the working mechanisms (i.e., charge generation/ 303 recombination/collection) of PSCs to be studied. ${ }^{94}$ In 304 particular, at low irradiance level $\left(P_{\text {inc }}<0.2\right.$ sun, region II) 305 the slope of the $V_{\mathrm{OC}}$ vs $\log \left(P_{\text {inc }}\right)$ plot is related to the electron 306 quasi-Fermi level, which is determined by the charge 307 accumulation and density of states in the ETL (i.e., $\mathrm{cTiO}_{2}+$ $\left.308 \mathrm{G} / \mathrm{mTiO}_{2}+\mathrm{G}\right) .{ }^{94}$ Consequently, the devices show almost the 309 same $V_{\mathrm{OC}}$ slopes under such conditions. For larger $P_{\text {inc }}(>0.2$ 310 sun, region III), the energy states of the ETL are fully filled, 311 and the charge generation and recombination rates within the 312 device determine the slope of the $V_{\mathrm{OC}}$ vs $\log \left(P_{\text {inc }}\right)$ plot. ${ }^{94}$ In 313 particular, the slope increase $(+7 \%)$ exhibited by the $\mathrm{MoS}_{2}$ 314 based device compared to the reference cell is attributed to an 315 increase in the charge recombination rate at the perovskite/ 316 HTM interface. In fact, the presence of $\mathrm{MoS}_{2}$ can activate 317 additional recombination pathways compared to the bare 318 spiro-OMeTAD, ${ }^{89}$ causing a slight decrease $(-0.3 \%)$ of the 319 average $V_{\mathrm{OC}}$ (see Figure 2a). Interestingly, the devices using 320 the $\mathrm{fMoS}_{2} \mathrm{ABL}$ show the lowest slope $\left(98 \mathrm{mV} \mathrm{dec}^{-1}\right)$ of the $321 V_{\mathrm{OC}}$ vs $\log \left(P_{\text {inc }}\right)$ plot in region III (Figure $\left.3 \mathrm{a}\right)$. This indicates 322 that the $\mathrm{fMoS}_{2} \mathrm{ABL}$ facilitates the hole transfer from the active 323 layer to the HTM compared to both reference and $\mathrm{MoS}_{2}$-based 324 cells. Steady-state PL measurements were performed to further 325 evaluate the capability of the $\mathrm{fMoS}_{2}$ ABLs to extract the 326 photogenerated holes from the perovskite. In fact, the hole327 extraction process hinders the radiative charge recombination 328 in the absorber material, ${ }^{95,96}$ which then shows a PL 329 quenching. ${ }^{97}$ Figure $3 \mathrm{~b}$ shows that the use of the $\mathrm{fMoS}_{2}$ $330 \mathrm{ABL}$ reduces the $\mathrm{PL}$ emission of the perovskite. Quantitatively, 331 the PL decreases by $9 \%$ in the presence of $\mathrm{fMoS}_{2} \mathrm{ABL}$ 332 compared to the reference device. Thus, this result indicates 333 that $\mathrm{fMoS}_{2} \mathrm{ABLs}$ effectively accelerate the hole-extraction 334 dynamics at the photoelectrode. Transient photocurrent 335 measurements can be additionally carried out to reveal 336 information about the charge carrier transport within the 337 PSCs. ${ }^{98}$ Figure $3 \mathrm{c}$ reports the transient photocurrent profile 338 recorded for both reference and $\mathrm{fMoS}_{2}$-based devices. The data 339 show fast rises of the photocurrent (in the order of $\mu \mathrm{s}$ ), which 340 are compatible with time scales associated with electron/hole 341 transport. $^{99,100}$ Thus, the faster photocurrent rise in the case of 342 the $\mathrm{fMoS}_{2}$-based device compared to the reference indicates 343 that the presence of the $\mathrm{fMoS}_{2} \mathrm{ABL}$ speeds up the hole charge 344 collection toward the $\mathrm{CE}$ of the devices. This improves the 345 charge collection efficiency, as also evidenced by incident346 photon-to-current conversion efficiency (IPCE) spectroscopy 347 measurements (Figure 3d). In particular, the integrated $J_{S C}$ for $348 \mathrm{fMoS}_{2}$-based cells increases by $4.8 \%$ compared to those of 349 reference devices, in agreement with the $J_{S C}$ values extrapolated 350 by the $I-V$ characteristics under 1 sun illumination (Figure $3512 \mathrm{~b})$. Overall, these data highlight the crucial role of the 352 functionalization of $\mathrm{MoS}_{2}$ for optimal engineering of the 353 perovskite/ABL/HTM interface and increasing simultaneously 354 the $J_{\mathrm{SC}}$ and the $V_{\mathrm{OC}}$ relative to those of reference devices.

355 Large-Area Modules. The upscaling of PSCs toward PSMs 356 induces several performance losses, the most relevant ones 357 related to the interfacial charge recombination and the 358 interconnection of the multiple cells in a module. ${ }^{101}$ In fact, 359 on the one hand, it is critical to deposit the various PSM layers over a large area with the same quality reached as in small-area 360 devices. Consequently, the interfacial charge recombination 361 experimentally increases with the increase of the interfacial 362 surface area. On the other hand, the typical PSM design 363 consists of a monolithic series interconnection of rectangular 364 subcells (with charge flowing across the smaller dimension), ${ }^{102} 365$ since it effectively prevents an excessive increase of the series 366 resistance of the FTO contact (whose sheet resistance is in the 367 order of tens of $\left.\Omega \square^{-1}\right){ }^{102}$ However, the overall series 368 resistance given by the other layers of the subcells still causes 369 resistive losses, which decrease the FF and, thus, the power 370 output of the PSMs. ${ }^{103}$ In this context, the performance losses 371 induced by the scaling-up process can be mitigated by the use 372 of a 2D material engineered structure investigated for small- 373 area devices, since it improves both the perovskite/CTL 374 interface and the conductivity of the ETL. Following this 375 rationale, the as-optimized mesoscopic PSCs were scaled up to 376 large-area PSMs. The reference module architecture (i.e., 377 without 2D materials) is hereafter named PSM-A. The 378 structure based on the $\mathrm{cTiO}_{2} / \mathrm{mTiO}_{2}+\mathrm{G}$ layer and c- 379 $\mathrm{TiO}_{2}+\mathrm{G} / \mathrm{TiO}_{2}+\mathrm{G}$ are named PSM-B and PSM-C, respectively, 380 while the fully optimized $2 \mathrm{D}$ material-engineered structure, 381 including the $\mathrm{fMoS}_{2} \mathrm{ABL}$, is named PSM-D. The detailed 382 description of the PSM manufacturing is reported in the 383 Supporting Information. Briefly, the module production 384 requires several additional steps compared to that of small- 385 area devices. These steps consist of patterning the module cells 386 by four laser ablation processes. ${ }^{83}$ In particular, a first laser 387 ablation step (P1) selectively removes the FTO to isolate 388 adjacent cells; a second laser ablation step (P2) removes the 389 complete ETL/perovskite/(ABL)/spiro-OMeTAD stack to 390 create the contact area between the cell vertical interconnec- 391 tion and the free FTO area. Lastly, a third ablation step (P3) 392 isolates the adjacent cells by removing the Au CE. For P2, the 393 power of a green laser $\left(\mathrm{Nd}: \mathrm{YVO}_{4}, \lambda=532 \mathrm{~nm}\right)$ was adjusted 394 carefully by evaluating the perovskite absorbance and the 395 eventual presence of 2D materials. First, PSM-C and PSM-D 396 with an active area of $82 \mathrm{~cm}^{2}$ were produced over a $12.5 \times 12.5397$ $\mathrm{cm}^{2}$ substrate. Such PSMs were obtained by 10 series- 398 connected cells (single-cell active area of $8.2 \mathrm{~cm}^{2}$ ). As shown 399 in Figure S3 and Table S1, the as-produced $\mathrm{fMoS}_{2}$-based 400 module (PSM-D) shows a PCE of $15.27 \%$, representing an 401 improvement of $12.6 \%$ compared to the PCE of PSM-C 402 $(13.56 \%)$. In fact, the $\mathrm{fMoS}_{2} \mathrm{ABL}$ in PSM-D increases the 403 module current $(+3.9 \%)$ and FF $(+8.3 \%)$ compared to PSM- 404 C. To further scale-up the PSM active area from 82 to $108 \mathrm{~cm}^{2}, 405$ the PSM layout was optimized in terms of cell width and dead 406 area between adjacent cells, leading to a final design consisting 407 of 22 series-connected cells with a single-cell active area of 4.9408 $\mathrm{cm}^{2}$ and a final aperture ratio (defined as $\mathrm{AR}=\mathrm{AA} /(\mathrm{AA}+\mathrm{DA}) 409$ in which AA is the active area and DA is the dead area) of $88 \% .410$ More in detail, in such a PSM layout, the P1, P2, and P3 411 scribes are 40,30 , and $30 \mu \mathrm{m}$, respectively, while the safety 412 area, i.e., the area between two adjacent laser scribes, is 135413 $\mu \mathrm{m}$. Figure $4 \mathrm{a}$ shows the photograph of an as-prepared large- $414 \mathrm{f} 4$ area PSM. The $I-V$ characteristics of the champion devices for 415 each PSM are reported in Figure 4b, evidencing the best 416 photovoltaic performance for PSM-D, followed by PSM-C. 417 The stabilized powers at maximum power point $\left(P_{\mathrm{MPP}}\right)$ for 418 PSM-C and PSM-D are also reported in Figure 4c, indicating 419 that the use of the $\mathrm{fMoS}_{2}$-based $\mathrm{ABL}$ increases the $P_{\mathrm{MPP}} 420$ $(+7.1 \%)$ compared to that of the PSM-C adopting the pristine 421 $\mathrm{MoS}_{2}$-based ABL. 
423 Figure 5a,b and Figure S4a,b report the photovoltaic 424 parameter statistics for the various PSMs extracted by the I$425 V$ characteristics under 1 sun illumination. The PCE 426 progressively increases passing from PSM-A to PSM-D (Figure $4275 \mathrm{a}$ ), confirming the crucial role of $2 \mathrm{D}$ material-based interface 428 engineering for boosting the photovoltaic performance. In 429 particular, the FF of the module (Figure 5b) undergoes an 430 improvement of $14 \%$ passing from an average value of $57 \%$ to 431 65\% for PSM-A and PSM-D, respectively. This improvement 432 can be attributed to the effect of $2 \mathrm{D}$ material-based interface 433 engineering, since all the investigated modules were realized 434 adopting the same optimized layout. Moreover, the $V_{\mathrm{OC}}$ and 435 the $J_{\text {SC }}$ improved passing from PSM-C to PSM-D (+3.64\% and $436+3.9 \%$, respectively; see Figure S4), thus confirming the trend 437 observed on small-area PSCs (see Figure 2a,b).

438 Notably, the fully 2D-material engineered modules (i.e., 439 PSM-D, comprising both graphene-based ETLs and $\mathrm{fMoS}_{2}$ 440 based ABLs) have shown an averaged PCE approaching 13\%, 441 with a record PCE of $13.4 \%$ and a record-high area-indexed 442 aperture PCE (AIAPCE $=$ AA $\times$ AR $\times$ PCE) ${ }^{83}$ of $1266.5 \%$ $443 \mathrm{~cm}^{2}$.

444 Finally, stability tests were performed by applying to the 445 PSMs prolonged thermal stress at $65{ }^{\circ} \mathrm{C}$ in an oven (ISOS$446 \mathrm{D} 2)^{104}$ and recording the corresponding PCE as a function of 447 the thermal stress time (Figure $5 \mathrm{c}$ ). The $\mathrm{fMoS}_{2}$-based module 448 (PSM-D) exhibited a clear PCE stabilization, as evidenced by a 449 remarkable improvement $(+370 \mathrm{~h})$ in the $T_{80}$ lifetime (defined 450 as the time span in which the device retains more than $80 \%$ of 451 its initial efficiency) compared to the one of module PSM-C. 452 Although a deeper investigation of the thermal-induced 453 degradation mechanisms is still ongoing, we believe that the 454 homogeneous $\mathrm{fMoS}_{2}$ interlayer (as demonstrated in Figure S5) 455 can be effective in (1) preventing the direct contact between 456 the spiro-OMeTAD dopants and the perovskite surface, which 457 promotes the interface degradation already experienced at 65 $458{ }^{\circ} \mathrm{C},{ }^{105}$ and (2) blocking atom migration from the Au electrode 459 to the perovskite. ${ }^{63}$

460 In conclusion, we have demonstrated 2D-material-engi461 neered PSMs with a PCE of $13.4 \%$ over an active area of 108 $462 \mathrm{~cm}^{2}$. This result, coupled with the superior thermal stability 463 shown by 2D-based PSMs compared to reference devices, 464 could pave the way for a feasible and reproducible scaling-up of 465 perovskite-based photovoltaic technologies.

\section{ASSOCIATED CONTENT}

\section{S Supporting Information}

468 The Supporting Information is available free of charge on the 469 ACS Publications website at DOI: 10.1021/acsenergy470 lett.9b01151.

471 Details on employed materials, cell and module 472 fabrication, material characterizations, electro-optical 473 measurement setup (IPCE, ARKEO, I-V character474 istics), and electrical characterization of the PSMs with 475 both active areas of $82 \mathrm{~cm}^{2}$ and $108 \mathrm{~cm}^{2}$ (PDF)

\section{AUTHOR INFORMATION}

\section{Corresponding Authors}

478 *Aldo Di Carlo. E-mail: aldo.dicarlo@uniroma2.it. 479 *Francesco Bonaccorso. E-mail: francesco.bonaccorso@iit.it. 480 ORCID

481 Sara Pescetelli: 0000-0002-3336-2425

482 Alessandro Lorenzo Palma: 0000-0002-1682-7032
Mirko Prato: 0000-0002-2188-8059

Francesco Bonaccorso: 0000-0001-7238-9420 484

Aldo Di Carlo: 0000-0001-6828-2380

485

Author Contributions

486

II (A.A. and S.P.) Both authors contributed equally to this work 487 Author Contributions

488 A.A., S.P., and A.D.C. conceived the work. A.A., S.P., A.L.P., 489 and A.D.C. performed the experiments on small and large area 490 devices, the electro-optical characterizations, and the stress 491 test. S.P. created the ToC/abstract graphic. L.N., S.B., B.M.G., 492 I.M., and F.B. produced and characterized the 2D materials. 493 The manuscript was written through contributions of all 494 authors. All authors have given approval to the final version of 495 the manuscript.

Notes

The authors declare no competing financial interest.

496

\section{ACKNOWLEDGMENTS}

This Project has received funding from the European Union's 500 Horizon 2020 research and innovation programme under 501 Grant Agreement No. 696656 (GrapheneCore1), No. 785219502 - GrapheneCore2, and Spearhead Project 3 "Graphene- 503 perovskite solar farm” during the Core 2 project. A.A. gratefully 504 acknowledges the financial support from the Ministry of 505 Education and Science of the Russian Federation in the 506 framework of Increase Competitiveness Program of NUST 507 «MISiS» (No. K3-2018-035), implemented by a govern- 508 mental decree dated 16th of March 2013, N 211. The authors 509 thank Michele Zarlenga (Officina meccanica, Dipartimento di 510 Fisica Università di Roma "Tor Vergata") for technical support 511 in the customization of the spin coater; A. E. del Rio Castillo 512 and R. Oropesa-Nunez (Graphene Laboratories facility, 513 Istituto Italiano di tecnologia, for useful discussion; the 514 Materials Characterization facility, Istituto Italiano di Tecno- 515 logia, for support in AFM data acquisition; and Electron 516 Microscopy facility, Istituto Italiano di Tecnologia, for support 517 in TEM data acquisition.

\section{REFERENCES}

519

(1) Huang, F.; Li, M.; Siffalovic, P.; Cao, G.; Tian, J. From Scalable 520 Solution Fabrication of Perovskite Films towards Commercialization 521 of Solar Cells. Energy Environ. Sci. 2019, 12 (2), 518-549. 522

(2) Green, M. A.; Ho-Baillie, A. Perovskite Solar Cells: The Birth of 523 a New Era in Photovoltaics. ACS Energy Lett. 2017, 2 (4), 822-830. 524

(3) https://www.nrel.gov/pv/assets/images/efficiency-chart.png 525 (accessed on 27 May 2019).

(4) https://www.oxfordpv.com/news/oxford-pv-sets-world-record- 527 perovskite-solar-cell (accessed on 27 May 2019).

(5) Raza, E.; Ahmad, Z.; Aziz, F. Stability of Organometal Halide 529 Perovskite Solar Cells and Role of HTMs : Recent Developments 530 And. RSC Adv. 2018, 8, 20952-20967.

(6) Yang, Z.; Zhang, S.; Li, L.; Chen, W. Research Progress on 532 Large-Area Perovskite Thin Films and Solar Modules. J. Mater. 2017, 533 $3,231-244$

(7) Correa-Baena, J.-P.; Saliba, M.; Buonassisi, T.; Grätzel, M.; 535 Abate, A.; Tress, W.; Hagfeldt, A. Promises and Challenges of 536 Perovskite Solar Cells. Science 2017, 358, 739-744.

(8) Park, N. G.; Grätzel, M.; Miyasaka, T.; Zhu, K.; Emery, K. 538 Towards Stable and Commercially Available Perovskite Solar Cells. 539 Nat. Energy 2016, 1 (11), 1-8.

(9) Wang, Q.; Chen, B.; Liu, Y.; Deng, Y.; Bai, Y.; Dong, Q.; Huang, 541 J. Scaling Behavior of Moisture-Induced Grain Degradation in 542 Polycrystalline Hybrid Perovskite Thin Films. Energy Environ. Sci. 543 2017, 10 (2), 516-522. 
545 (10) Bryant, D.; Aristidou, N.; Pont, S.; Sanchez-Molina, I.; 546 Chotchunangatchaval, T.; Wheeler, S.; Durrant, J. R.; Haque, S. A. 547 Light and Oxygen Induced Degradation Limits the Operational 548 Stability of Methylammonium Lead Triiodide Perovskite Solar Cells. 549 Energy Environ. Sci. 2016, 9, 1655-1660.

550 (11) Aristidou, N.; Sanchez-Molina, I.; Chotchuangchutchaval, T.; 551 Brown, M.; Martinez, L.; Rath, T.; Haque, S. A. The Role of Oxygen 552 in the Degradation of Methylammonium Lead Trihalide Perovskite 553 Photoactive Layers. Angew. Chem., Int. Ed. 2015, 54 (28), 8208-8212. 554 (12) Nie, W.; Tsai, H.; Asadpour, R.; Blancon, J.-C.; Neukirch, A. J.; 555 Gupta, G.; Crochet, J. J.; Chhowalla, M.; Tretiak, S.; Alam, M. A.; 556 et al. Solar Cells. High-Efficiency Solution-Processed Perovskite Solar 557 Cells with Millimeter-Scale Grains. Science 2015, 347 (6221), 522558525.

559 (13) Conings, B.; Drijkoningen, J.; Gauquelin, N.; Babayigit, A.; 560 D'Haen, J.; D’Olieslaeger, L.; Ethirajan, A.; Verbeeck, J.; Manca, J.; 561 Mosconi, E.; et al. Intrinsic Thermal Instability of Methylammonium 562 Lead Trihalide Perovskite. Adv. Energy Mater. 2015, 5 (15), 1500477. 563 (14) Qiu, L.; Ono, L. K.; Qi, Y. Advances and Challenges to the 564 Commercialization of Organic-inorganic Halide Perovskite Solar Cell 565 Technology. Mater. Today Energy 2018, 7, 169-189.

566 (15) Juarez-Perez, E. J.; Hawash, Z.; Raga, S. R.; Ono, L. K.; Qi, Y. 567 Thermal Degradation of $\mathrm{CH}_{3} \mathrm{NH}_{3} \mathrm{PbI}_{3}$ Perovskite into $\mathrm{NH}_{3}$ and $\mathrm{CH}_{3} \mathrm{I}$ 568 Gases Observed by Coupled Thermogravimetry-Mass Spectrometry 569 Analysis. Energy Environ. Sci. 2016, 9 (11), 3406-3410.

570 (16) Rong, Y.; Hu, Y.; Mei, A.; Tan, H.; Saidaminov, M. I.; Seok, S. $571 \mathrm{Il}$; Mcgehee, M. D.; Sargent, E. H.; Han, H. Challenges for 572 Commercializing Perovskite Solar Cells. Science 2018, 361, eaat8235. 573 (17) Li, Z.; Klein, T. R.; Kim, D. H.; Yang, M.; Berry, J. J.; Van Hest, 574 M. F. A. M.; Zhu, K. Scalable Fabrication of Perovskite Solar Cells. 575 Nat. Rev. Mater. 2018, 3, 1-20.

576 (18) Yang, M.; Li, Z.; Reese, M. O.; Reid, O. G.; Kim, D. H.; Siol, S.; 577 Klein, T. R.; Yan, Y.; Berry, J. J.; Van Hest, M. F. A. M.; et al. 578 Perovskite Ink with Wide Processing Window for Scalable High579 Efficiency Solar Cells. Nat. Energy 2017, 2 (5), 1-9.

580 (19) Jeon, N. J.; Noh, J. H.; Kim, Y. C.; Yang, W. S.; Ryu, S.; Seok, S. 581 Solvent Engineering for High-Performance Inorganic-Organic Hybrid 582 Perovskite Solar Cells. Nat. Mater. 2014, 13 (July), 897.

583 (20) Xiao, M.; Huang, F.; Huang, W.; Dkhissi, Y.; Zhu, Y.; 584 Etheridge, J.; Gray-Weale, A.; Bach, U.; Cheng, Y. B.; Spiccia, L. A 585 Fast Deposition-Crystallization Procedure for Highly Efficient Lead 586 Iodide Perovskite Thin-Film Solar Cells. Angew. Chem., Int. Ed. 2014, 58753 (37), 9898-9903.

588 (21) Deng, Y.; Zheng, X.; Bai, Y.; Wang, Q.; Zhao, J.; Huang, J. 589 Surfactant-Controlled Ink Drying Enables High-Speed Deposition of 590 Perovskite Films for Efficient Photovoltaic Modules. Nat. Energy 591 2018, 3 (7), 560-566.

592 (22) Konstantakou, M.; Perganti, D.; Falaras, P.; Stergiopoulos, T. 593 Anti-Solvent Crystallization Strategies for Highly Efficient Perovskite 594 Solar Cells. Crystals 2017, 7 (10), 291.

595 (23) Kim, J.; Yun, J. S.; Cho, Y.; Lee, D. S.; Wilkinson, B.; Soufiani, 596 A. M.; Deng, X.; Zheng, J.; Shi, A.; Lim, S.; et al. Overcoming the 597 Challenges of Large-Area High-Efficiency Perovskite Solar Cells. ACS 598 Energy Lett. 2017, 2 (9), 1978-1984.

599 (24) Razza, S.; Castro-Hermosa, S.; Di Carlo, A.; Brown, T. M. 600 Research Update: Large-Area Deposition, Coating, Printing, and 601 Processing Techniques for the Upscaling of Perovskite Solar Cell 602 Technology. APL Mater. 2016, 4 (9), 091508-091522.

603 (25) Li, J.; Munir, R.; Fan, Y.; Niu, T.; Liu, Y.; Zhong, Y.; Yang, Z.; 604 Tian, Y.; Liu, B.; Sun, J.; et al. Phase Transition Control for High605 Performance Blade-Coated Perovskite Solar Cells. Joule 2018, 2 (7), 606 1313-1330.

607 (26) Kim, Y. Y.; Yang, T. Y.; Suhonen, R.; Välimäki, M.; Maaninen, 608 T.; Kemppainen, A.; Jeon, N. J.; Seo, J. Gravure-Printed Flexible 609 Perovskite Solar Cells: Toward Roll-to-Roll Manufacturing. Adv. Sci. 610 2019, 6 (7), 1802094.

611 (27) Uličná, S.; Dou, B.; Kim, D. H.; Zhu, K.; Walls, J. M.; Bowers, J. 612 W.; van Hest, M. F. A. M. Scalable Deposition of High-Efficiency
Perovskite Solar Cells by Spray-Coating. ACS Appl. Energy Mater. 613 2018, 1 (5), 1853-1857.

(28) Bishop, J. E.; Routledge, T. J.; Lidzey, D. G. Advances in Spray- 615 Cast Perovskite Solar Cells. J. Phys. Chem. Lett. 2018, 9 (8), 1977- 616 1984.

(29) Park, M.; Cho, W.; Lee, G.; Hong, S. C.; Kim, M.-c.; Yoon, J.; 618 Ahn, N.; Choi, M. Highly Reproducible Large-Area Perovskite Solar 619 Cell Fabrication via Continuous Megasonic Spray Coating of 620 $\mathrm{CH}_{3} \mathrm{NH}_{3} \mathrm{PbI}_{3}$. Small 2019, 15 (1), 1804005 .

621

(30) Najafi, L.; Taheri, B.; Martín-García, B.; Bellani, S.; Di 622 Girolamo, D.; Agresti, A.; Oropesa-Nuñez, R.; Pescetelli, S.; Vesce, L.; 623 Calabrò, E.; et al. $\mathrm{MoS}_{2}$ Quantum Dot/Graphene Hybrids for 624 Advanced Interface Engineering of a $\mathrm{CHNH}_{3} \mathrm{PbI}_{3}$ Perovskite Solar 625 Cell with an Efficiency of over 20\%. ACS Nano 2018, 12 (11), 626 10736-10754.

627

(31) Yang, G.; Wang, C.; Lei, H.; Zheng, X.; Qin, P.; Xiong, L.; 628 Zhao, X.; Yan, Y.; Fang, G. Interface Engineering in Planar Perovskite 629 Solar Cells: Energy Level Alignment, Perovskite Morphology Control 630 and High Performance Achievement. J. Mater. Chem. A 2017, 5 (4), 631 $1658-1666$.

(32) Bai, Y.; Meng, X.; Yang, S. Interface Engineering for Highly 633 Efficient and Stable Planar P-i-n Perovskite Solar Cells. Adv. Energy 634 Mater. 2018, 8 (5), 1701883.

(33) Grancini, G.; Roldàn-Carmona, C.; Zimmermann, I.; Mosconi, 636 E.; Lee, X.; Martineau, D.; Narbey, S.; Oswald, F.; De Angelis, F.; 637 Graetzel, M.; Nazeeruddin, M. K. One-Year stable perovskite solar 638 cells by 2D/3D Interface Engineering. Nat. Commun. 2017, 8, 15684. 639

(34) Zhao, L.; Kerner, R. A.; Xiao, Z.; Lin, Y. L.; Lee, K. M.; 640 Schwartz, J.; Rand, B. P. Redox Chemistry Dominates the 641 Degradation and Decomposition of Metal Halide Perovskite 642 Optoelectronic Devices. ACS Energy Lett. 2016, 1 (3), 595-602. 643

(35) Zhou, H.; Chen, Q.; Li, G.; Luo, S.; Song, T.; Duan, H.-S.; 644 Hong, Z.; You, J.; Liu, Y.; Yang, Y. Interface Engineering of Highly 645 Efficient Perovskite Solar Cells. Science 2014, 345 (6196), 542-546. 646

(36) Seo, Y.; Kim, E.; Cho, S.; Kim, S.; Na, S. High-Performance 647 Planar Perovskite Solar Cells : Influence of Solvent upon Perform- 648 ance. Appl. Mater. Today 2017, 9, 598-604.

(37) Jung, E. H.; Jeon, N. J.; Park, E. Y.; Moon, C. S.; Shin, T. J.; 650 Yang, T. Y.; Noh, J. H.; Seo, J. Efficient, Stable and Scalable 651 Perovskite Solar Cells Using Poly(3-Hexylthiophene). Nature 2019, 652 567 (7749), 511-515.

653

(38) Chen, W.; Yin, X.; Que, M.; Xie, H.; Liu, J.; Yang, C.; Guo, Y.; 654 Wu, Y.; Que, W. A Comparative Study of Planar and Mesoporous 655 Perovskite Solar Cells with Printable Carbon Electrodes. J. Power 656 Sources 2019, 412, 118-124. 657

(39) Dagar, J.; Castro-Hermosa, S.; Gasbarri, M.; Palma, A. L.; Cina, 658 L.; Matteocci, F.; Calabrò, E.; Di Carlo, A.; Brown, T. M. Efficient 659 Fully Laser-Patterned Flexible Perovskite Modules and Solar Cells 660 Based on Low-Temperature Transport Layers. Nano Res. 2018, 11, 661 2669-2681.

(40) Bu, T.; Li, J.; Zheng, F.; Chen, W.; Wen, X.; Ku, Z.; Peng, Y.; 663 Zhong, J.; Cheng, Y. B.; Huang, F. Universal Passivation Strategy to 664 Slot-Die Printed $\mathrm{SnO}_{2}$ for Hysteresis-Free Efficient Flexible Perov- 665 skite Solar Module. Nat. Commun. 2018, 9 (1), 1-10.

(41) Calabrò, E.; Matteocci, F.; Palma, A. L.; Vesce, L.; Taheri, B.; 667 Carlini, L.; Pis, I.; Nappini, S.; Dagar, J.; Battocchio, C.; et al. Solar 668 Energy Materials and Solar Cells Low Temperature, Solution- 669 Processed Perovskite Solar Cells and Modules with an Aperture 670 Area Efficiency of 11\%. Sol. Energy Mater. Sol. Cells 2018, 185, 136- 671 144.

(42) Christians, J. A.; Schulz, P.; Tinkham, J. S.; Schloemer, T. H.; 673 Harvey, S. P.; Tremolet De Villers, B. J.; Sellinger, A.; Berry, J. J.; 674 Luther, J. M. Tailored Interfaces of Unencapsulated Perovskite Solar 675 Cells for $>1,000$ h Operational Stability. Nat. Energy 2018, 3 (1), 68- 676 74.

(43) Christians, J. A.; Zhang, F.; Bramante, R. C.; Reese, M. O.; 678 Schloemer, T. H.; Sellinger, A.; Van Hest, M. F. A. M.; Zhu, K.; Berry, 679 J. J.; Luther, J. M. Stability at Scale: Challenges of Module 680 
681 Interconnects for Perovskite Photovoltaics. ACS Energy Lett. 2018, 3 682 (10), 2502-2503.

683 (44) Yang, M.; Kim, D. H.; Klein, T. R.; Li, Z.; Reese, M. O.; 684 Tremolet de Villers, B. J.; Berry, J. J.; van Hest, M. F. A. M.; Zhu, K. 685 Highly Efficient Perovskite Solar Modules by Scalable Fabrication and 686 Interconnection Optimization. ACS Energy Lett. 2018, 3, 322-328. 687 (45) Di Giacomo, F.; Shanmugam, S.; Fledderus, H.; Bruijnaers, B. 688 J.; Verhees, W. J. H.; Dorenkamper, M. S.; Veenstra, S. C.; Qiu, W.; 689 Gehlhaar, R.; Merckx, T.; et al. Up-Scalable Sheet-to-Sheet 690 Production of High Efficiency Perovskite Module and Solar Cells 691 on 6-in. Substrate Using Slot Die Coating. Sol. Energy Mater. Sol. Cells 692 2018, 181, 53-59.

693 (46) Hong, S.; Lee, J.; Kang, H.; Kim, G.; Kee, S.; Lee, J.; Jung, S.; 694 Park, B.; Kim, S.; Back, H.; et al. High-Efficiency Large-Area 695 Perovskite Photovoltaic Modules Achieved via Electrochemically 696 Assembled Metal-Filamentary Nanoelectrodes. Sci. Adv. 2018, 4, 697 eaat 3604.

698 (47) Hu, Y.; Si, S.; Mei, A.; Rong, Y.; Liu, H.; Li, X.; Han, H. Stable 699 Large-Area $\left(10 \times 10 \mathrm{Cm}^{2}\right)$ Printable Mesoscopic Perovskite Module 700 Exceeding 10\% Efficiency. Sol. RRL 2017, 1 (2), 1600019.

701 (48) Duan, M.; Hu, Y.; Mei, A.; Rong, Y.; Han, H. Printable Carbon702 Based Hole-Conductor-Free Mesoscopic Perovskite Solar Cells: From 703 Lab to Market. Mater. Today Energy 2018, 7, 221-231.

704 (49) Chen, H.; Yang, S. Carbon-Based Perovskite Solar Cells 705 without Hole Transport Materials: The Front Runner to the Market? 706 Adv. Mater. 2017, 29 (24), 1603994-1604010.

707 (50) De Rossi, F.; Baker, J. A.; Beynon, D.; Hooper, K. E. A.; 708 Meroni, S. M. P.; Williams, D.; Wei, Z.; Yasin, A.; Charbonneau, C.; 709 Jewell, E. H.; et al. All Printable Perovskite Solar Modules with 198 $710 \mathrm{Cm} 2$ Active Area and Over 6\% Efficiency. Adv. Mater. Technol. 2018, $7113,1800156$.

712 (51) Balis, N.; Stratakis, E.; Kymakis, E. Graphene and Transition 713 Metal Dichalcogenide Nanosheets as Charge Transport Layers for 714 Solution Processed Solar Cells. Mater. Today 2016, 19 (10), 580715594.

716 (52) Kakavelakis, G.; Kymakis, E.; Petridis, K. 2D Materials Beyond 717 Graphene for Metal Halide Perovskite Solar Cells. Adv. Mater. 718 Interfaces 2018, 5, 1800339.

719 (53) Agresti, A.; Pescetelli, S.; Palma, A. L.; Del Rio Castillo, A. E.; 720 Konios, D.; Kakavelakis, G.; Razza, S.; Cina, L.; Kymakis, E.; et al. 721 Graphene Interface Engineering for Perovskite Solar Modules: $12.6 \%$ 722 Power Conversion Efficiency over $50 \mathrm{Cm}^{2}$ Active Area. ACS Energy 723 Lett. 2017, 2 (1), 279-287.

724 (54) Agresti, A.; Pescetelli, S.; Taheri, B.; Del Rio Castillo, A. E.; 725 Cinà, L.; Bonaccorso, F.; Di Carlo, A. Graphene-Perovskite Solar 726 Cells Exceed 18\% Efficiency: A Stability Study. ChemSusChem 2016, 9 727 (18), 2609-2619.

728 (55) Biccari, F.; Gabelloni, F.; Burzi, E.; Gurioli, M.; Pescetelli, S.; 729 Agresti, A.; Del Rio Castillo, A. E.; Ansaldo, A.; Kymakis, E.; 730 Bonaccorso, F.; et al. Graphene-Based Electron Transport Layers in 731 Perovskite Solar Cells: A Step-Up for an Efficient Carrier Collection. 732 Adv. Energy Mater. 2017, 7, 1701349.

733 (56) Palma, A. L.; Cinà, L.; Pescetelli, S.; Agresti, A.; Raggio, M.; 734 Paolesse, R.; Bonaccorso, F.; Di Carlo, A. Reduced Graphene Oxide 735 as Efficient and Stable Hole Transporting Material in Mesoscopic 736 Perovskite Solar Cells. Nano Energy 2016, 22, 349-360.

737 (57) Agresti, A.; Pescetelli, S.; Cinà, L.; Konios, D.; Kakavelakis, G.; 738 Kymakis, E.; Carlo, A. Di. Efficiency and Stability Enhancement in 739 Perovskite Solar Cells by Inserting Lithium-Neutralized Graphene 740 Oxide as Electron Transporting Layer. Adv. Funct. Mater. 2016, 26, $7412686-2694$.

742 (58) Busby, Y.; Agresti, A.; Pescetelli, S.; Di Carlo, A.; Noel, C.; 743 Pireaux, J.; Houssiau, L. Aging Effects in Interface-Engineered 744 Perovskite Solar Cells with 2D Nanomaterials : A Depth pro Fi Le 745 Analysis. Mater. Today Energy 2018, 9, 1-10.

746 (59) Ahn, N.; Kwak, K.; Jang, M. S.; Yoon, H.; Lee, B. Y.; Lee, J.; 747 Pikhitsa, P. V.; Byun, J.; Choi, M. Trapped Charge-Driven 748 Degradation of Perovskite Solar Cells. Nat. Commun. 2016, 7, 13422.
(60) Asghar, M. I.; Zhang, J.; Wang, H.; Lund, P. D. Device Stability 749 of Perovskite Solar Cells - A Review. Renew. Sustain. Energy Rev. 750 2017, 77, 131-146.

(61) Arora, N.; Dar, M. I.; Hinderhofer, A.; Pellet, N.; Schreiber, F.; 752 Zakeeruddin, S. M.; Grätzel, M. Perovskite Solar Cells with CuSCN 753 Hole Extraction Layers Yield Stabilized Efficiencies Greater than 20\%. 754 Science 2017, 358, 768-771.

(62) Brunetti, B.; Cavallo, C.; Ciccioli, A.; Gigli, G.; Latini, A. On 756 the Thermal and Thermodynamic (In) Stability of Methylammonium 757 Lead Halide Perovskites. Sci. Rep. 2016, 6, 1-12.

(63) Domanski, K.; Mine, N.; Nazeeruddin, M. K.; Abate, A.; Saliba, 759 M.; Tress, W.; Hagfeldt, A.; Grätzel, M.; Correa-Baena, J.-P. Not All 760 That Glitters Is Gold: Metal Migration- Induced Degradation in 761 Perovskite Solar Cells. ACSNano 2016, 10 (6), 6306-6314. 762

(64) Walsh, A.; Stranks, S. D. Taking Control of Ion Transport in 763 Halide Perovskite Solar Cells. ACS Energy Lett. 2018, 3 (8), 1983- 764 1990.

(65) Li, C.; Guerrero, A.; Huettner, S.; Bisquert, J. Unravelling the 766 Role of Vacancies in Lead Halide Perovskite through Electrical 767 Switching of Photoluminescence. Nat. Commun. 2018, 9 (1), 1-8. 768

(66) Kim, N.; Min, Y. H.; Noh, S.; Cho, E.; Jeong, G.; Ahn, S.; Lee, 769 J. S.; Kim, S.; Ihm, K.; Ahn, H.; et al. Investigation of Thermally 770 Induced Degradation in $\mathrm{CH}_{3} \mathrm{NH}_{3} \mathrm{PbI}_{3}$ Perovskite Solar Cells Using 771 In-Situ Synchrotron Radiation Analysis. Sci. Rep. 2017, 7 (March), 1- 772

(67) Saliba, M.; Matsui, T.; Seo, J.-Y.; Domanski, K.; Correa-Baena, 774 J.-P.; Nazeeruddin, M. K.; Zakeeruddin, S. M.; Tress, W.; Abate, A.; 775 Hagfeldt, A.; et al. Cesium-Containing Triple Cation Perovskite Solar 776 Cells: Improved Stability, Reproducibility and High Efficiency. Energy 777 Environ. Sci 2016, 9, 1989-1997.

(68) Jung, M.; Kim, C.; Jeon, J.; Yang, S.; Seo, J.; Noh, J. H.; Il Seok, 779 S. Thermal Stability of CuSCN Hole Conductor-Based Perovskite 780 Solar Cells. ChemSusChem 2016, 9, 2592-2596.

(69) Rolston, N.; Watson, B. L.; Bailie, C. D.; Mcgehee, M. D.; 782 Bastos, J. P.; Gehlhaar, R.; Kim, J.; Vak, D.; Mallajosyula, A. T.; 783 Gupta, G.; et al. Mechanical Integrity of Solution-Processed 784 Perovskite Solar Cells. Extrem. Mech. Lett. 2016, 9, 353-358. 785

(70) Hawash, Z.; Ono, L. K.; Qi, Y. Recent Advances in Spiro- 786 MeOTAD Hole Transport Material and Its Applications in Organic - 787 Inorganic Halide Perovskite Solar Cells. Adv. Mater. 2018, 5, 788 1700623.

(71) Wang, S.; Sina, M.; Parikh, P.; Uekert, T.; Shahbazian, B.; 790 Devaraj, A.; Meng, Y. S. Role of 4- Tert -Butylpyridine as a Hole 791 Transport Layer Morphological Controller in Perovskite Solar Cells. 792 Nano Lett. 2016, 16 (9), 5594-5600.

(72) Snaith, H. J.; Grätzel, M. Enhanced Charge Mobility in a 794 Molecular Hole Transporter via Addition of Redox Inactive Ionic 795 Dopant: Implication to Dye-Sensitized Solar Cells. Appl. Phys. Lett. 796 2006, 89 (26), 262114-262117.

(73) Nguyen, W. H.; Bailie, C. D.; Unger, E. L.; Mcgehee, M. D. 798 Enhancing the Hole-Conductivity of Spiro-OMeTAD without 799 Oxygen or Lithium Salts by Using Spiro(TFSI) $)_{2}$ in Perovskite and 800 Dye- Sensitized Solar Cells. J. Am. Chem. Soc. 2014, 136, 10996- 801 11001

(74) Liu, J.; Wu, Y.; Qin, C.; Yang, X.; Yasuda, T.; Islam, A.; Zhang, 803 K.; Peng, W.; Chen, W.; Han, L. A Dopant-Free Hole-Transporting 804 Material for Efficient and Stable Perovskite Solar Cells. Energy 805 Environ. Sci. 2014, 7 (9), 2963-2967.

(75) Sanchez, R. S.; Mas-Marza, E. Light-Induced Effects on Spiro- 807 OMeTAD Films and Hybrid Lead Halide Perovskite Solar Cells. Sol. 808 Energy Mater. Sol. Cells 2016, 158, 189-194.

(76) Jena, A. K.; Ikegami, M.; Miyasaka, T. Severe Morphological 810 Deformation of Spiro-OMeTAD in $\left(\mathrm{CH}_{3} \mathrm{NH}_{3}\right) \mathrm{PbI}_{3}$ Solar Cells at 811 High Temperature. ACS Energy Lett. 2017, 2 (8), 1760-1761. 812

(77) Graetzel, M. Photoelectrochemical Cells. Nature 2001, 414, 813 $338-344$.

(78) Chung, I.; Lee, B.; He, J.; Chang, R. P. H.; Kanatzidis, M. G. 815 All-Solid-State Dye-Sensitized Solar Cells with High Efficiency. 816 Nature 2012, 485, 486-490. 
818 (79) Kwon, K. C.; Choi, K. S.; Kim, S. Y. Increased Work Function 819 in Few-Layer Graphene Sheets via Metal Chloride Doping. Adv. Funct. 820 Mater. 2012, 22 (22), 4724-4731.

821 (80) Hu, C.; Bai, Y.; Xiao, S.; Zhang, T.; Meng, X.; Ng, W. K.; Yang, 822 Y.; Wong, K. S.; Chen, H.; Yang, S. Tuning A-Site Cation 823 Composition of FA Perovskite for Efficient And. J. Mater. Chem. A 824 2017, 5, 21858-21865.

825 (81) Jiang, Y.; Leyden, M. R.; Qiu, L.; Wang, S.; Ono, L. K.; Wu, Z.; 826 Juarez-perez, E. J.; Qi, Y. Combination of Hybrid CVD and Cation 827 Exchange for Upscaling Cs-Substituted Mixed Cation Perovskite Solar 828 Cells with High Efficiency and Stability. Adv. Funct. Mater. 2018, 28, 8291703835.

830 (82) Schulz, P.; Edri, E.; Kirmayer, S.; Hodes, G.; Cahen, D.; Kahn, 831 A. Interface Energetics in Organo-Metal Halide Perovskite-Based 832 Photovoltaic Cells. Energy Environ. Sci. 2014, 7 (4), 1377-1381.

833 (83) Palma, A. L.; Matteocci, F.; Agresti, A.; Pescetelli, S.; Calabro, 834 E.; Vesce, L.; Christiansen, S.; Schmidt, M.; Di Carlo, A. Laser835 Patterning Engineering for Perovskite Solar Modules With 95\% 836 Aperture Ratio. IEEE J. Photovoltaics 2017, 7, 1674-1680.

837 (84) Agresti, A.; Pescetelli, S.; Najafi, L.; Castillo, A. E. D. R.; Busby, 838 Y.; Di Carlo, A. Graphene and Related 2D Materials for High Efficient 839 and Stable Perovskite Solar Cells. In Proceedings of the 17th IEEE 840 International Conference on Nanotechnology Pittsburgh; 2017; pp 145841150.

842 (85) Volonakis, G.; Giustino, F. Ferroelectric Graphene-Perovskite 843 Interfaces. J. Phys. Chem. Lett. 2015, 6 (13), 2496-2502.

844 (86) Huang, P.; Wang, Z.; Liu, Y.; Zhang, K.; Yuan, L.; Zhou, Y.; 845 Song, B.; Li, Y. Water-Soluble 2D Transition Metal Dichalcogenides 846 as Hole Transport Layer for High Efficient and Stable p-i-n Perovskite 847 Solar Cells. ACS Appl. Mater. Interfaces 2017, 9 (30), 25323-25331. 848 (87) Kim, Y. G.; Kwon, K. C.; Le, Q. V.; Hong, K.; Jang, H. W.; $849 \mathrm{Kim}, \mathrm{S}$. Y. Atomically Thin Two-Dimensional Materials as Hole 850 Extraction Layers in Organolead Halide Perovskite Photovoltaic Cells. 851 J. Power Sources 2016, 319, 1-8.

852 (88) Dasgupta, U.; Chatterjee, S.; Pal, A. J. Thin- Film Formation of $8532 \mathrm{D} \mathrm{MoS}_{2}$ and Its Application as a Hole-Transport Layer in Planar 854 Perovskite Solar Cells. Sol. Energy Mater. Sol. Cells 2017, 172 (April), 855 353-360.

856 (89) Capasso, A.; Matteocci, F.; Najafi, L.; Prato, M.; Buha, J.; Cinà, 857 L.; Pellegrini, V.; Di Carlo, A.; Bonaccorso, F. Few-Layer $\mathrm{MoS}_{2}$ Flakes 858 as Active Buffer Layer for Stable Perovskite Solar Cells. Adv. Energy 859 Mater. 2016, 6 (16), 1600920.

860 (90) Chen, X.; Berner, N. C.; Backes, C.; Duesberg, G. S.; $861 \mathrm{McDonald}, \mathrm{A}$. R. Functionalization of Two-Dimensional $\mathrm{MoS}_{2}$ : On 862 the Reaction between $\mathrm{MoS}_{2}$ and Organic Thiols. Angew. Chem., Int. 863 Ed. 2016, 55 (19), 5803-5808.

864 (91) Förster, A.; Gemming, S.; Seifert, G.; Tománek, D. Chemical 865 and Electronic Repair Mechanism of Defects in $\mathrm{MoS}_{2}$ Monolayers. 866 ACS Nano 2017, 11 (10), 9989-9996.

867 (92) Ding, Q.; Czech, K. J.; Zhao, Y.; Zhai, J.; Hamers, R. J.; Wright, 868 J. C.; Jin, S. Basal-Plane Ligand Functionalization on Semiconducting $8692 \mathrm{H}-\mathrm{MoS}_{2}$ Monolayers. ACS Appl. Mater. Interfaces 2017, 9 (14), 870 12734-12742.

871 (93) Brown, P. R.; Kim, D.; Lunt, R. R.; Zhao, N.; Bawendi, M. G.; 872 Grossman, J. C.; Bulović, V. Energy Level Modification in Lead 873 Sulfide Quantum Dot Thin Films through Ligand Exchange. ACS 874 Nano 2014, 8 (6), 5863-5872.

875 (94) Gouda, L.; Gottesman, R.; Ginsburg, A.; Keller, D. A.; Haltzi, 876 E.; Hu, J.; Tirosh, S.; Anderson, A. Y.; Zaban, A.; Boix, P. P. Open 877 Circuit Potential Build-Up in Perovskite Solar Cells from Dark 878 Conditions to 1 Sun. J. Phys. Chem. Lett. 2015, 6, 4640-4645.

879 (95) Bhosale, J. S.; Moore, J. E.; Wang, X.; Bermel, P.; Lundstrom, 880 M. S. Steady-State Photoluminescent Excitation Characterization of 881 Semiconductor Carrier Recombination. Rev. Sci. Instrum. 2016, 87 882 (1), 013104-013111.

883 (96) Jiménez-López, J.; Cambarau, W.; Cabau, L.; Palomares, E. 884 Charge Injection, Carriers Recombination and HOMO Energy Level 885 Relationship in Perovskite Solar Cells. Sci. Rep. 2017, 7 (1), 1-10.
(97) Wang, X.; Bhosale, J.; Moore, J.; Kapadia, R.; Bermel, P.; Javey, 886 A.; Lundstrom, M. Photovoltaic Material Characterization with 887 Steady State and Transient Photoluminescence. IEEE J. Photovoltaics 888 2015, 5 (1), 282-287.

(98) Alsari, M.; Pearson, A. J.; Wang, J. T.; Wang, Z.; Greenham, N. 890 C.; Snaith, H. J.; Lilliu, S.; Friend, R. H.; Montisci, A. Degradation 891 Kinetics of Inverted Perovskite Solar Cells. Sci. Rep. 2018, 8, 5977. 892

(99) Pearson, A. J.; Hopkinson, P. E.; Couderc, E.; Domanski, K.; 893 Abdi-jalebi, M.; Greenham, N. C. Critical Light Instability in CB/DIO 894 Processed PBDTTT-EFT:PC ${ }_{71} \mathrm{BM}$ Organic Photovoltaic Devices. 895 Org. Electron. 2016, 30, 225-236.

(100) Li, Z.; Gao, F.; Greenham, N. C.; Mcneill, C. R. Comparison 897 of the Operation of Polymer/Fullerene, Polymer/Polymer, and 898 Polymer/Nanocrystal Solar Cells: A Transient Photocurrent and 899 Photovoltage Study. Adv. Funct. Mater. 2011, 21 (8), 1419-1431. 900

(101) Razza, S.; Di Giacomo, F.; Matteocci, F.; Cinà, L.; Palma, A. 901 L.; Casaluci, S.; Cameron, P.; D'Epifanio, A.; Licoccia, S.; Reale, A.; 902 et al. Perovskite Solar Cells and Large Area Modules (100 Cm 2) 903 Based on an Air Flow-Assisted PbI 2 Blade Coating Deposition 904 Process. J. Power Sources 2015, 277 (2015), 286-291.

(102) Bartlome, R.; Strahm, B.; Sinquin, Y.; Feltrin, A.; Ballif, C. 906 Laser Applications in Thin-Film Photovoltaics. Appl. Phys. B: Lasers 907 Opt. 2010, 100 (2), 427-436.

(103) Rakocevic, L.; Gehlhaar, R.; Merckx, T.; Qiu, W.; Paetzold, U. 909 W.; Fledderus, H.; Poortmans, J. Interconnection Optimization for 910 Highly Efficient Perovskite Modules. IEEE J. Photovoltaics 2017, 7911 (1), 404-408.

(104) Reese, M. O.; Gevorgyan, S. A.; Jørgensen, M.; Bundgaard, E.; 913 Kurtz, S. R.; Ginley, D. S.; Olson, D. C.; Lloyd, M. T.; Morvillo, P.; 914 Katz, E. A.; et al. Consensus Stability Testing Protocols for Organic 915 Photovoltaic Materials and Devices. Sol. Energy Mater. Sol. Cells 2011, 916 95 (5), 1253-1267.

(105) Divitini, G.; Cacovich, S.; Matteocci, F.; Di Carlo, A.; Ducati, 918 C.; Cinà, L. In Situ Observation of Heat-Induced Degradation of 919 Perovskite Solar Cells. Nat. Energy 2016, 1, 15012. 